\title{
Three-dimensional structural modeling of a low permeability reservoir in the Banqiao formation of the Maxi Oilfield
}

\author{
Yongqiang $\mathrm{Li}^{1}$ · Jiagen $\mathrm{Hou}^{2} \cdot \mathrm{XiaO}_{\mathrm{Guo}}^{3}$
}

Received: 15 April 2018 / Accepted: 7 February 2019 / Published online: 13 February 2019

(c) The Author(s) 2019

\begin{abstract}
This paper presents a three-dimensional geological modeling method for low permeability reservoirs based on core, logging, seismic, and dynamic data. Matrix and fractures are two types of reservoir space. This method includes two-step modeling methods, and different methods are used to establish a matrix model and fracture model. As a low permeability reservoir, Maxi Oilfield has entered the high water cut stage, and developing a precise three-dimensional structural model that can reflect the spatial distribution of the reservoir is an urgent task. First, the gravity flow channel deposition was determined by core observations and the characteristics of gravity flow reservoirs are described. On this basis, a three-dimensional quantitative geological model of the matrix is established using the sequential indicator simulation. The ant-tracking technique is used to identify the fracture development in Maxi Oilfield, and two groups of fractures, $50^{\circ}-100^{\circ}$ in an NE direction and $30^{\circ}-35^{\circ}$ in an NE direction, are identified as the main reservoirs. The discrete fracture distribution model is established deterministically, and then, the fracture model is modified by the distribution of fractures reflected comprehensively by the water flooding front, microseismic, and dynamic data. This three-dimensional structural model can guide the development of water injection wells in Maxi Oilfield.
\end{abstract}

Keywords Maxi Oilfield $\cdot$ Low permeability reservoir $\cdot$ Sequential indicator simulation $\cdot$ Ant-tracking $\cdot$ Three-dimensional structural modeling

\section{Introduction}

Maxi Oilfield is located in the central part of Beidagang fault zone in Huanghua depression, and was discovered in September 1978. Oilfield engineers have done considerable research on the structure, sedimentation, and physical parameters of Maxi Oilfield. However, publicly published literature is rarely documented. The structure of Maxi Oilfield is a complete reverse drag dome anticline with a gentle structure and few faults (Fig. 1). The structural form is complete, the closure degree is large, the distribution of oil layers is concentrated, and the connectivity is strong.

Yongqiang Li

liyongqiangz@163.com

1 Petroleum Exploration and Production Research Institute, Sinopec, Beijing 100083, China

2 College of Geosciences, China University of Petroleum, Beijing 102249, China

3 Research Institute, CNOOC, Beijing 100027, China
The oil-bearing formation is the Banqiao member of the Shahejie formation of the Paleogene, with a burial depth $3785-4030 \mathrm{~m}$, an oil-bearing area of $17.8 \mathrm{~km}^{2}$, and reserves of $724.1 \times 10^{4} \mathrm{t}$. The strata of the Banqiao member represent the gravity flow facies, and the reservoir's lithology consists of fine sandstone and siltstone. The average porosity is $12.9 \%$ and the average permeability is approximately $3 \times 10^{-3} \mu \mathrm{m}^{2}$, which shows that Maxi Oilfield is a low porosity and low permeability reservoir. After nearly 40 years of development, the oilfield entered the high water cut stage with production continuing to decline and water continuing to rise. The per-day oil production has dropped from $226 \mathrm{t} /$ day by the end of 1998 to the current rate of $5.13 \mathrm{t} /$ day, the comprehensive water content increased from $59.31 \%$ to the current rate of $91.57 \%$, and the oil production rate decreased from $1.27 \%$ to the current rate of $0.03 \%$. Therefore, the oilfield can only maintain the status of low speed mining, and further improvements on the level of reservoir quantitative descriptions are urgent.

The three-dimensional structural model provides quantitative descriptions of reservoirs, characterizes the 


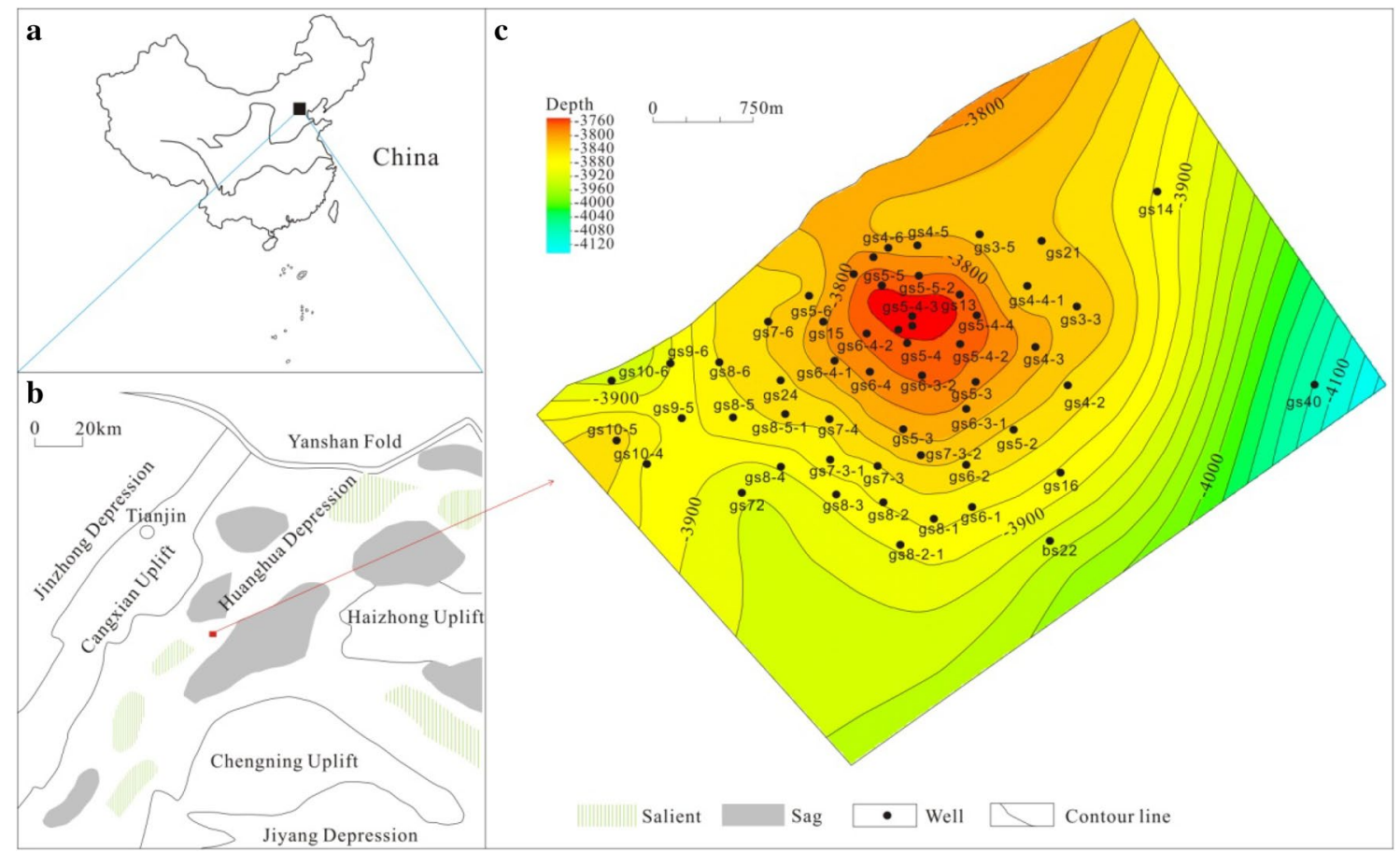

Fig. 1 Location map of Maxi Oilfield in Huanghua depression. a Location map of Huanghua Depression. b Tectonic location map of Huanghua Depression. c Tectonic map of Maxi Oilfield

distribution and changes of reservoirs in three-dimensional space in the subsurface and can provide a geological basis for direct optimization of an oilfield development plan (Tureyen and Caers 2005). The objective of this study is to establish a precise three-dimensional geological model based on reservoir characteristics and provide a basis for describing the distribution of remaining oil and drawing up a practical potential tapping scheme. The main contents include the following two aspects: (1) build the matrix model to improve the accuracy of reservoir predictions according the geological understanding and seismic data and (2) set up an accurate fracture model to strengthen the quantitative study of the fractures.

\section{Methods}

Establishing the model for a low permeability reservoir consists of using different methods to build the matrix model and fracture model. Sequential indicator simulation discretizes geological variables into a series of indicative variables. The Kriging estimation algorithm is used to estimate the estimated values of indicative variables and to estimate the probability distribution of unknown location variables. Each node of the grid to be simulated randomly extracts the values of the cumulative probability distribution function as its interpolation along a random path; each simulated value is treated as an indicator variable, and then recomputed. Then, the cumulative probability distribution function is calculated to obtain the simulation value of the next grid node in the random path (Pyrcz and Deutsch 2014). Sequential indicator simulation is an effective method to establish the sedimentary facies model using seismic data as the constraint and is used to build matrix model. Ant-tracking technology, based on the principle of the ant colony algorithm, is a population-based heuristic bionic algorithm. Anttracking can highlight the discontinuity of seismic data and can strengthen studies of fracture characteristics (Luo et al. 2016). Ant-tracking directly extracts the information from the seismic data; it can also provide a low noise, clear fracture traces of the data and is used to build the fracture model. According to the injection-production relationship and the oil well water injection effect, the fracture is described and the established fracture model is modified.

\section{Materials and results}

Well data, seismic data, and dynamic data are the basic data required for modeling. Well data are hard data with a high vertical resolution. Seismic data have the advantage of high lateral resolution and can be used as soft data for inter-well predictions. Dynamic data can modify the static data modeling results. Data in this article include: (1) 7 well 
cores of $0.1 \mathrm{~m}$ in diameter and $350 \mathrm{~m}$ in length; (2) a reservoir interpretation of 55 wells based on integrated wireline $\operatorname{logs}$ (e.g., spontaneous potential curve, gamma, resistivity, neutron, and sonic); (3) the dynamic information of wells including water injection, dynamic data, production data and waterflooding front data; and (4) three-dimensional seismic impedance data over an area of $17.8 \mathrm{~km}^{2}$ with a sampling interval of $1 \mathrm{~ms}$ and a grid size of $15 \times 15 \mathrm{~m}$.

\section{Matrix modeling}

There are many kinds of slump deformation structures formed in the core of a gravity flow channel, such as an orbicular structure (Fig. 2a), a banded sandbody embedded in mudstone (Fig. 2b), mud gravels of varying sizes in sandstone (Fig. 2c), and mudstone debris (Fig. 2d). Furthermore, massive bedding, graded bedding (Fig. 2e-g), nature fractures (Fig. 2h, i), an abrupt interface of the gravity flow channel (Fig. 2j), and parallel lamination (Fig. 2 k) can also be found in the cores. The sand is fine sandstone and siltstone of a varying thickness with gray and gray brown color, and the mud is dark gray and gray black, thus indicating deep-water sedimentary characteristics (Fig. 21). The rock types are mainly feldspar sandstone and lithic feldspathic sandstone, which have a low compositional maturity, medium sorting, sub circular and angular, and roundness. Seismic inversion technology uses seismic, well logging, geological and other data to reveal the spatial geometry of the subsurface target (oil reservoirs or coal layers, etc.)

The impedance is an important attribute in distinguishing sand and mud with a high lateral resolution. Maxi Oilfield is characterized by large reservoir thickness, oil reservoir concentration distribution and good reservoir connectivity, and the results of log constrained impedance inversion can be used to identify the boundary of sand and mud (Fig. 3a). Thus, the impedance can be used for predicting of sand body distribution. The impedance of sand is greater than $1950 \mathrm{~g} /$ $\mathrm{cm}^{3} \mathrm{~m} / \mathrm{s}$ and the other impedance is mud in the study area (Fig. 3 b).

The stochastic modeling method admits that the distribution of geological parameters is random, and there are some uncertain factors in the understanding of it. The reliability of the simulation results can be reduced by adding reliable sub-variables (Aarnes 2004; Chen et al. 2014). Sequential
Fig. 2 Core photographs representative of low permeability reservoirs in Maxi Oilfield. a Orbicular structure at $3971.1 \mathrm{~m}$ in well gs72. b Banded sandbody embedded in mudstone at $4047.9 \mathrm{~m}$ in well gs72. c Mud gravels of varying sizes in sandstone at $3958.5 \mathrm{~m}$ in well gs72. d Mudstone debris at $4050.7 \mathrm{~min}$ well gs72. e Massive bedding with fine sandstone at $3936.0 \mathrm{~m}$ in well gs5-5. f Massive bedding with siltstone at $3887.1 \mathrm{~m}$ in well gs $21 . \mathbf{g}$ Massive bedding with higher mud content at $3887.1 \mathrm{~m}$ in well gs72. h Massive bedding with fractures at $3885.4 \mathrm{~m}$ in well gs 21 . i Fractures with calcite at $3937.8 \mathrm{~m}$ in well gs72. j Abrupt interface of gravity flow channel at $3912.7 \mathrm{~m}$ in well g5-5. $\mathbf{k}$ Parallel lamination at $4046.4 \mathrm{~m}$ in well gs72. 1 Dark gray and gray black mud at $3906.2 \mathrm{~m}$ in well gs21
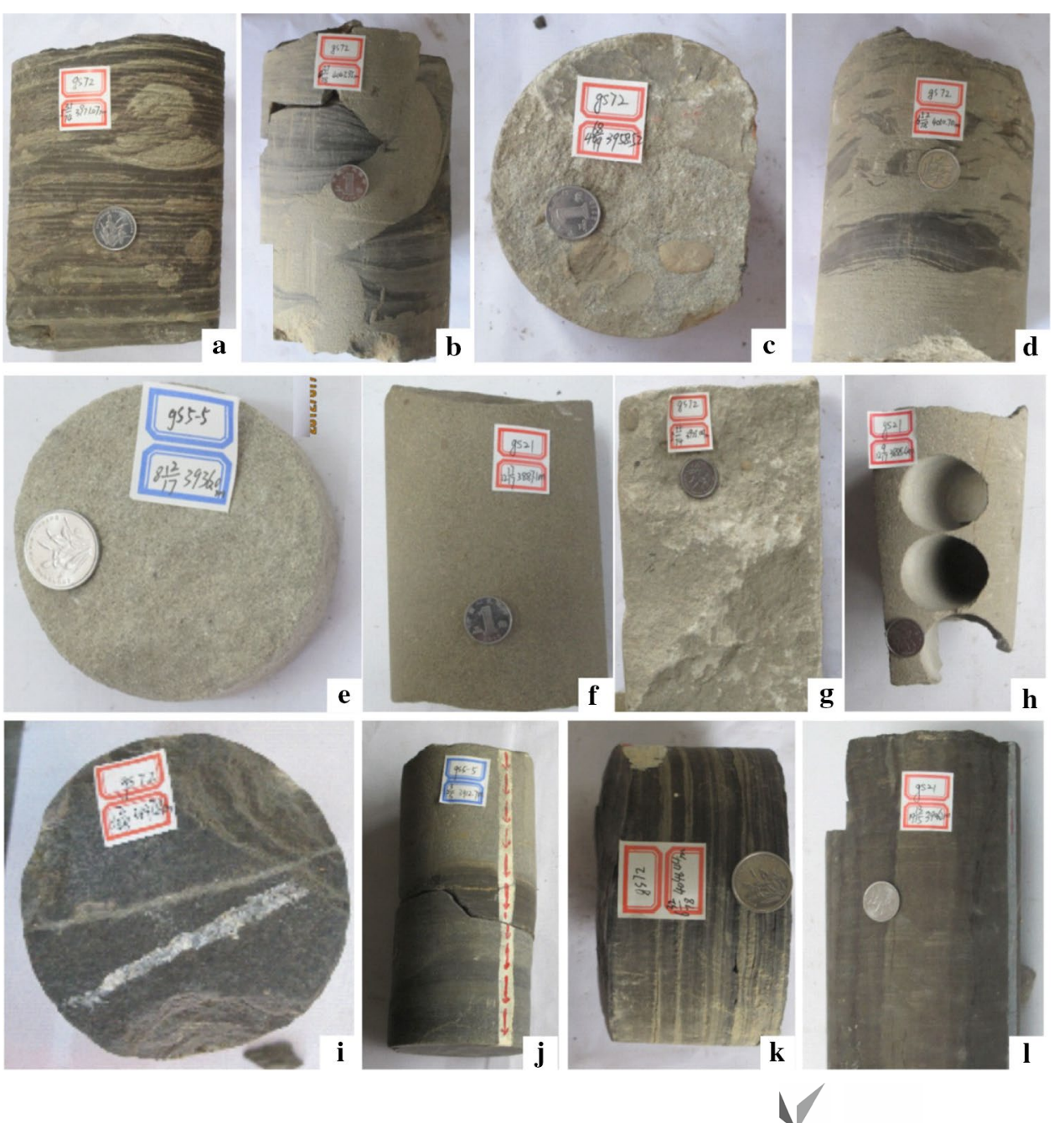

مدينة الملك عبدالعزيز 
Fig. 3 Relationship of impedance between wells and seismic data. a Vertical section of seismic impedance in Well gs5-4-3, gs5-4-2 and gs5-3. b Seismic impedance histogram of sand and mud from 52 wells
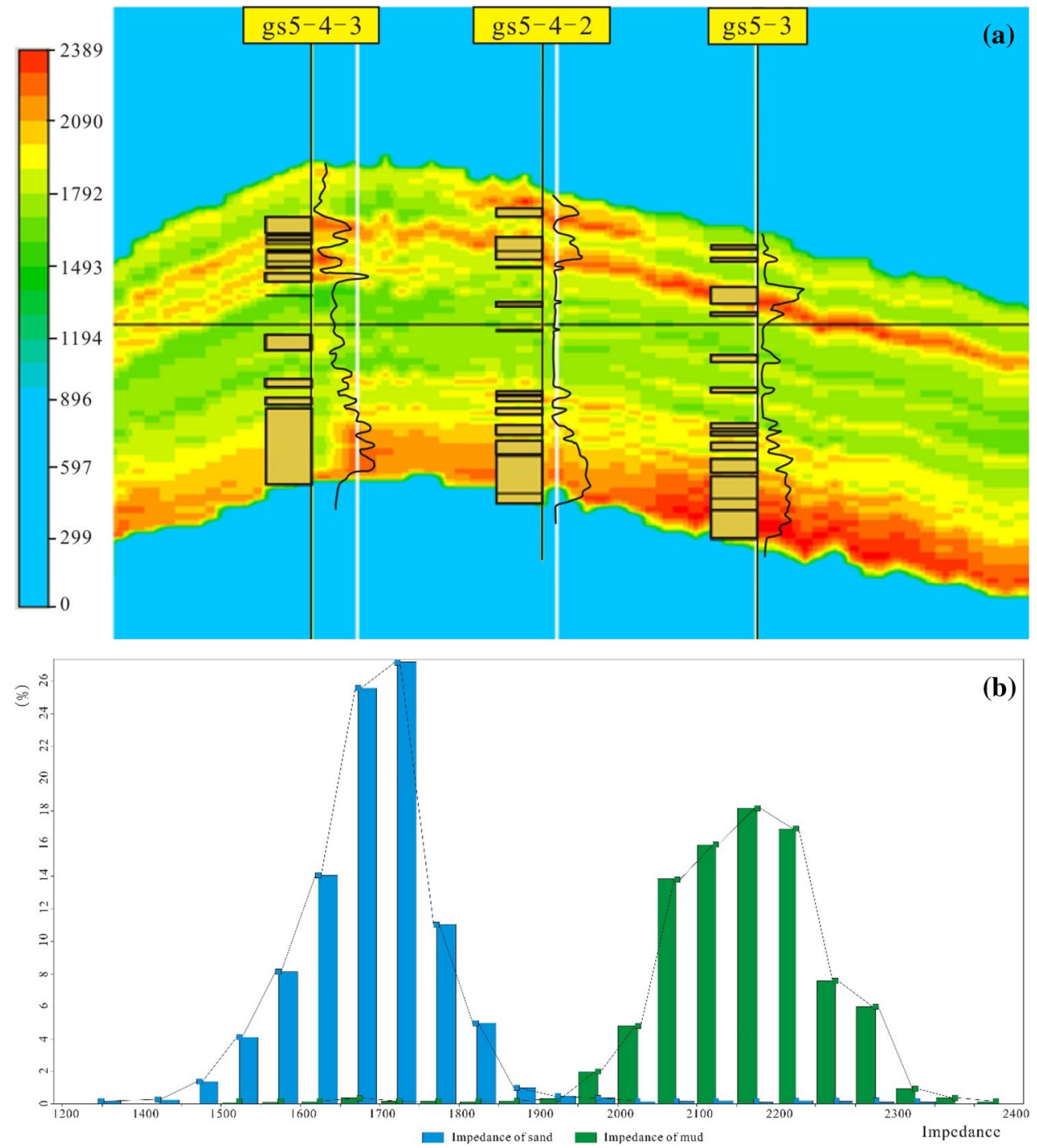

indicator simulation is a widely used random simulation technique (Journel 1983; Journel and Alabert 1988). Based on the variogram function (Fig. 4), the matrix model is established by the sequential indicator simulation algorithm using well data as hard data and the impedance attribute as soft data (Fig. 5). The simulation results can both match the well log data and better reflect the inter-well reliability (Fig. 6a, b).

\section{Fracture modeling}

The discrete fracture network (DFN) model is an effective technique realizing the description of the fracture system from the geometric form to the seepage behavior. It has been widely used to describe the distribution of fractures in threedimensional space by means of ant-tracking (Lang and Guo 2013; Xu et al. 2011; Yao et al. 2010). Ant-tracking directly extracts fracture information from seismic data using the factor exclusion and the azimuth anisotropy methods (Zhou et al. 2015). Ant-tracking creates a new fault attribute, highlights the azimuths' corresponding section characteristics, and automatically extracts a seismic attribute volume of a detailed discontinuous reflection (Fig. 7a). Based on the fracture fragments extracted automatically by the anttracking, the fracture model is established by deterministic modeling (Fig. 8). In Maxi Oilfield, one of the natural fracture groups is between $\mathrm{NE} 50^{\circ}-100^{\circ}$, and the other group is NE $30^{\circ}-35^{\circ}$ (Table 1). The range of the fracture length is $250-500 \mathrm{~m}$.

In the case of fracturing or high-pressure water injection, according to the Mohr-Kulun criterion, there will be a microseismic along the inlet area due to the increase of formation pressure. Based on the continuous acquisition and recording of the microseismic data recorded by the water injection, a front area can be obtained. This can be used to describe the single well fracture and, therefore, determine the connection between injection wells and the water production and the water drive direction. The waterflooding 

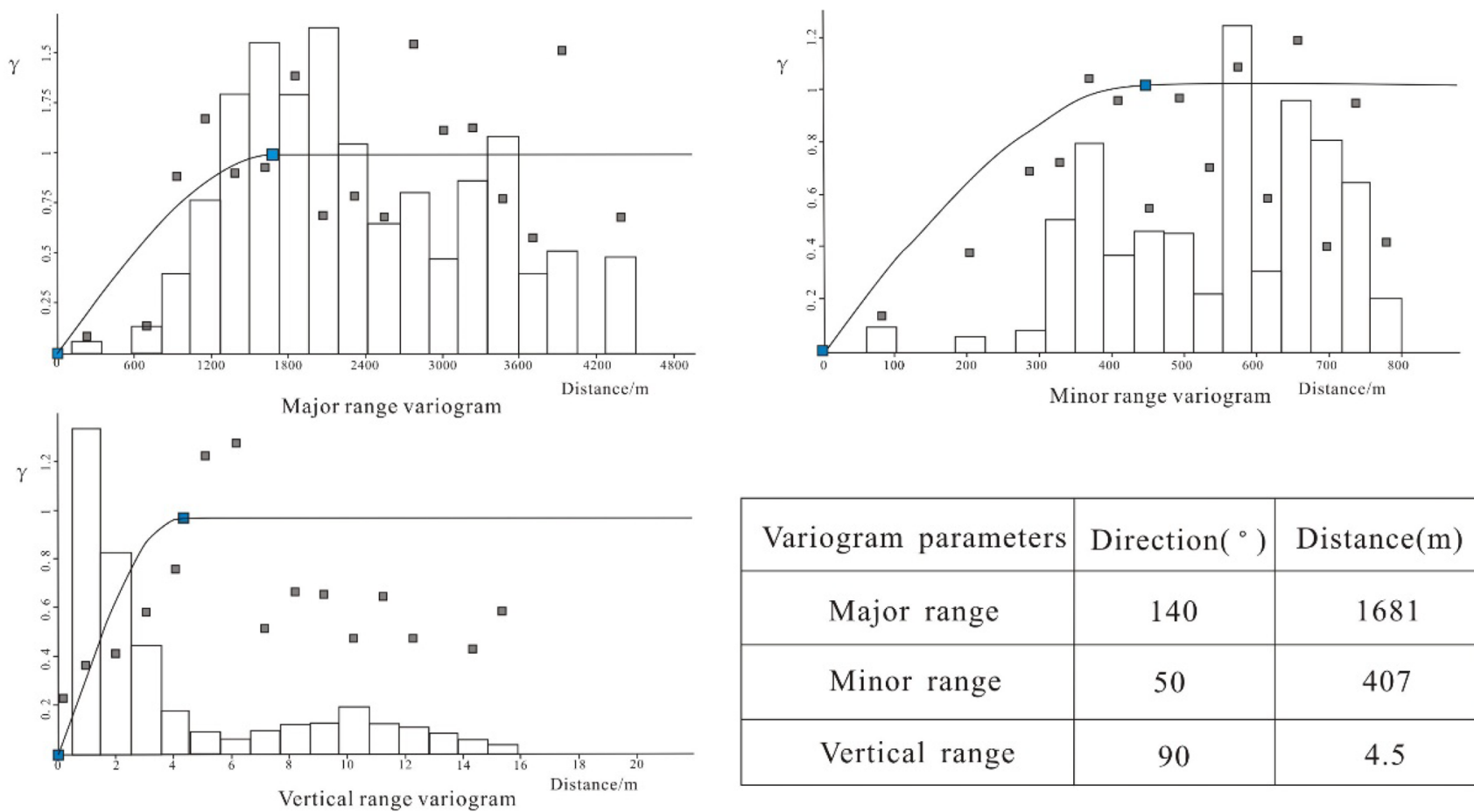

\begin{tabular}{|c|c|c|}
\hline Variogram parameters & Direction $\left(^{\circ}\right)$ & Distance $(m)$ \\
\hline Major range & 140 & 1681 \\
\hline Minor range & 50 & 407 \\
\hline Vertical range & 90 & 4.5 \\
\hline
\end{tabular}

Fig. 4 Parameters of variograms of Maxi Oilfield

Fig. 5 Three-dimensional facies model of Maxi Oilfield

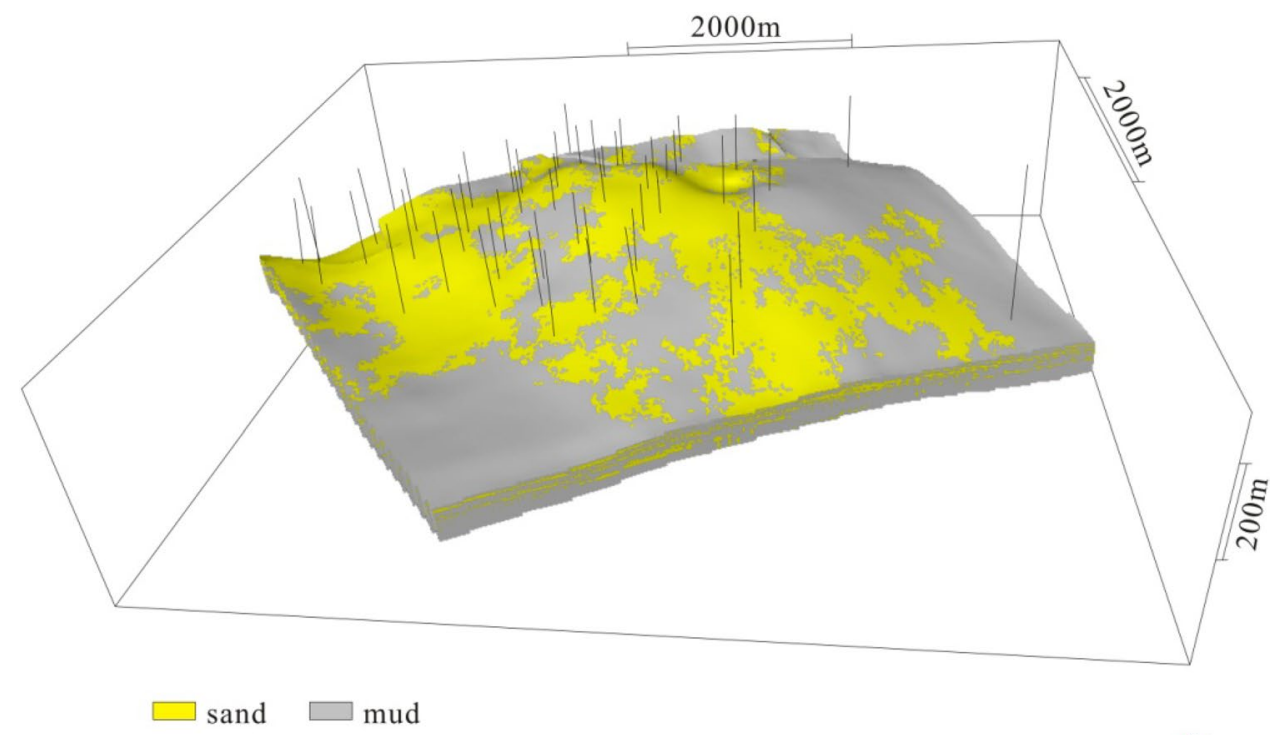

front monitoring results of Well gs4-3 show that the range and direction of the dominant seepage zone and the average direction of the fractures are all in the range of $50^{\circ}-60^{\circ}$ between the north and east(Fig. 9a, b), which shows a strong agreement with ant-tracking prediction. This also proves that the single well micro-fractures are consistent with the development law of fractures in Maxi Oilfield.
A production curve can reflect the current state of fractures. Taking injection Well gs4-3 as an example, the amount of water injection of Well gs4-3 was increased in April 1998, and well gs4-4-1 obtained a strong result in 3 months and the per-day oil production increased from 12.6 to $35.02 \mathrm{t} /$ day (Fig. 7c). Meanwhile, there was no significant change in water content or the per-day oil production of Well gs4-2 
Fig. 6 Vertical section and quality control of facies model and $\mathrm{t}$ in Maxi Oilfield. a Vertical section of facies model in Well gs5-4-3, gs5-4-2 and gs5-3. b Relationship of well logs, upscaled data and simulation result
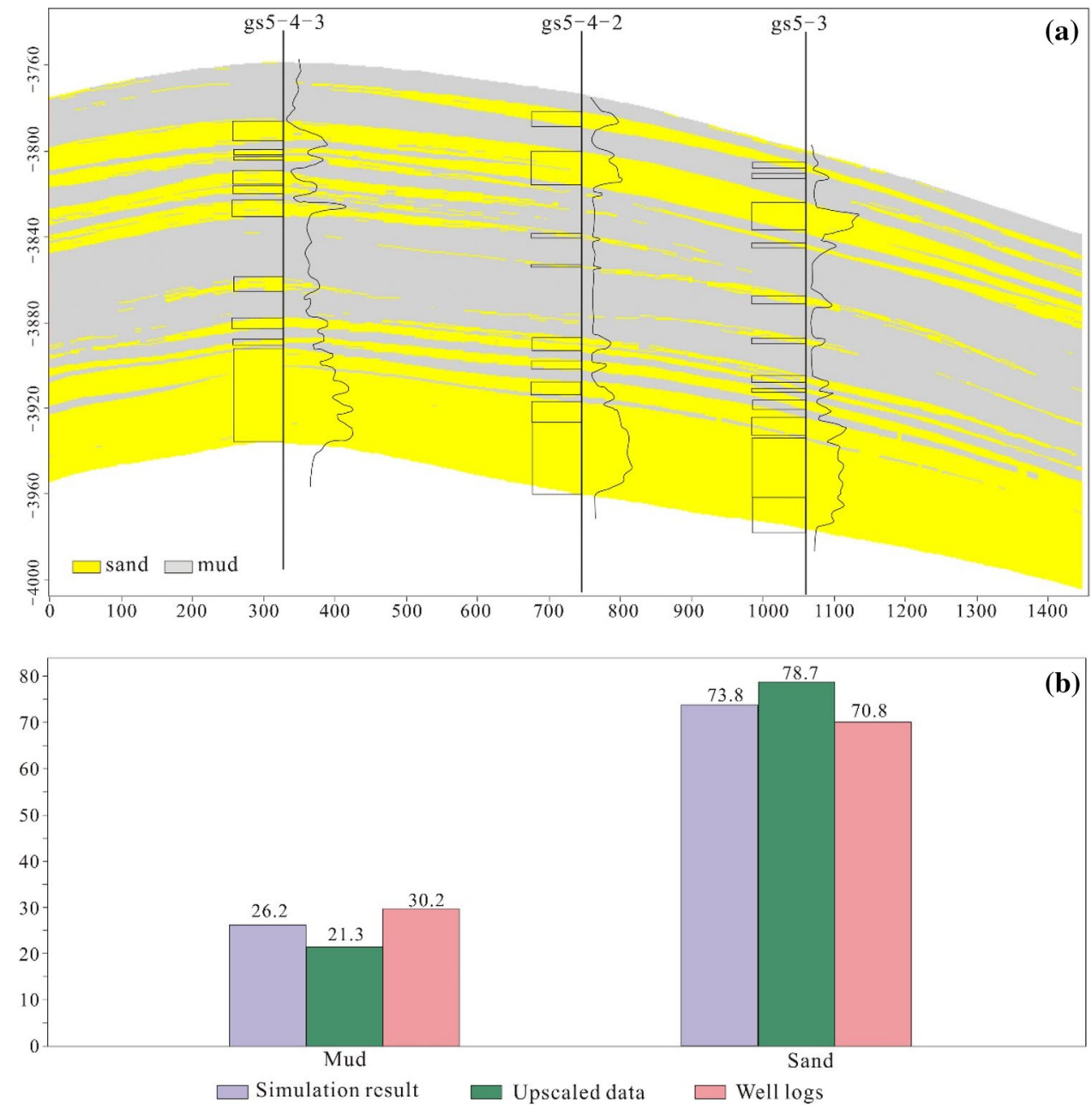

in 1 year (Fig. 7d). This shows that fractures exist around these wells, and the existence of fractures can improve the reservoir's percolation ability and form the dominant seepage channel. Therefore, the injected water rapidly advances along the direction of fracture development, and the effect of water flooding in the oil well is stronger than that in other directions. The production practice shows that Well gs44-1 is more effective than Well gs4-2.It can be inferred that the direction of the fracture development is parallel to that of the Well gs4-3to Well gs4-4-1, which is consistent with the direction of the fracture development monitored for the water front. This is also consistent with the ant-body prediction of the fracture development.

When comparing the fractures reflected by the ant-body slices with the existing 14 wells by water injection, 13 well are matched closely, and only gs6-4 is not consistent. The fitting rate is $93 \%$ and it can be used to forecast the entire area's fractures effectively.

The fracture model is modified based on the results of the waterflooding front and dynamic data, and the final fracture model is consistent with the actual production and has a prediction function. This quantitative fracture description can provide a new way for modeling similar reservoir fractures.

\section{Discussion}

The biggest advantage of the sequential indicator simulation is that it can simulate the complex anisotropic geological phenomena and the extreme value of continuous distribution. A variogram reflects geologists' understanding geological phenomena. For different types of variables (lithology) with a different distribution, different variogram functions can be specified to construct anisotropic simulation parameters. Ant-tracking overcomes the subjectivity of traditional seismic interpretation, ensures the accuracy of the description of the fractures, and has obvious advantages in the description of the spatial distribution of fractures.

The model effectively integrated core, logging, seismic, and dynamic data to establish a three-dimensional structural model of low permeability reservoirs. Seismic 


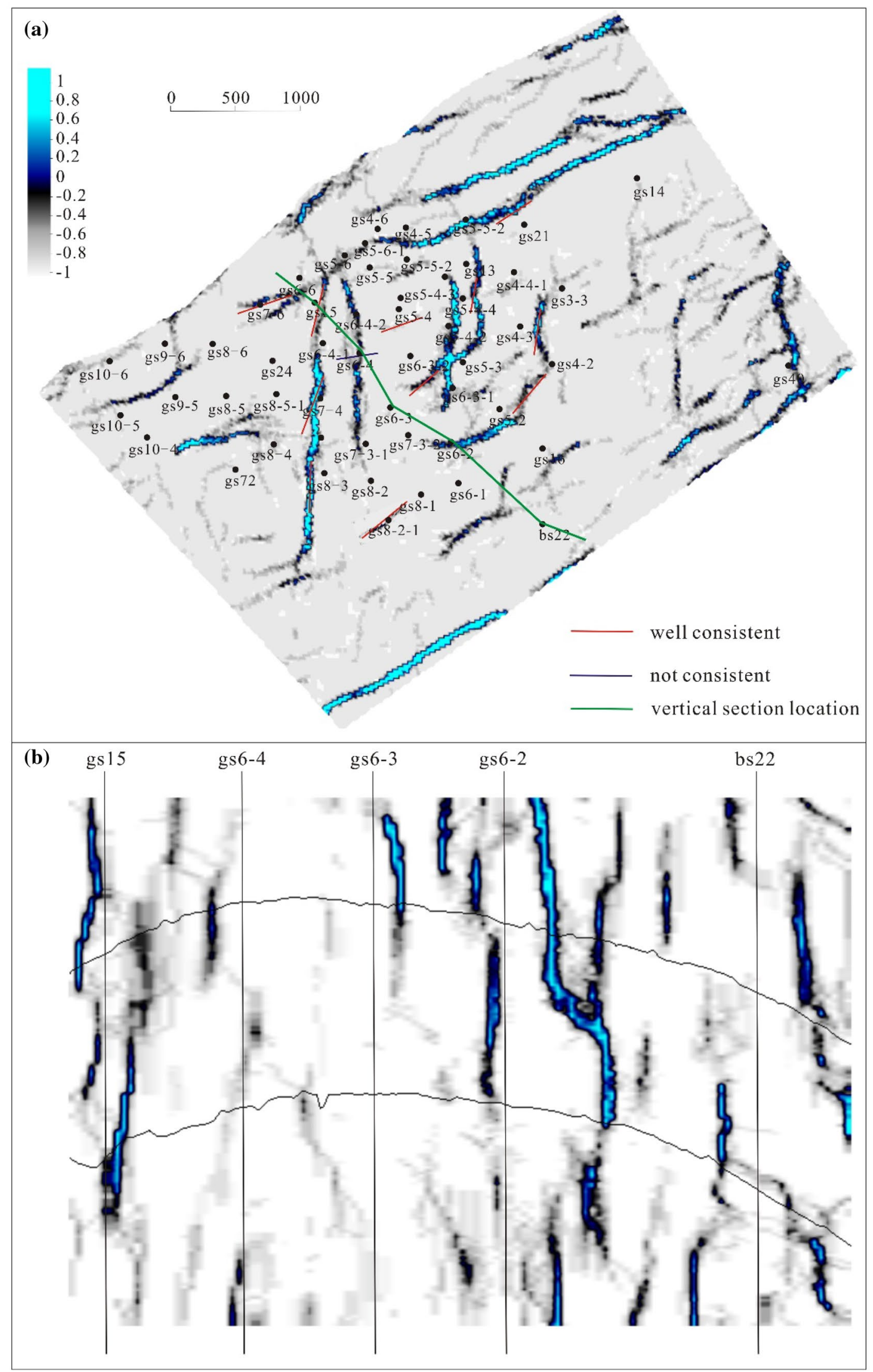

Fig. 7 Ant-tracking prediction of fractures in Maxi Oilfield. a Slice of ant-tracking attribute. b. Vertical section of ant-tracking attribute 
Fig. 8 Fracture model built by ant-tracking in Maxi Oilfield

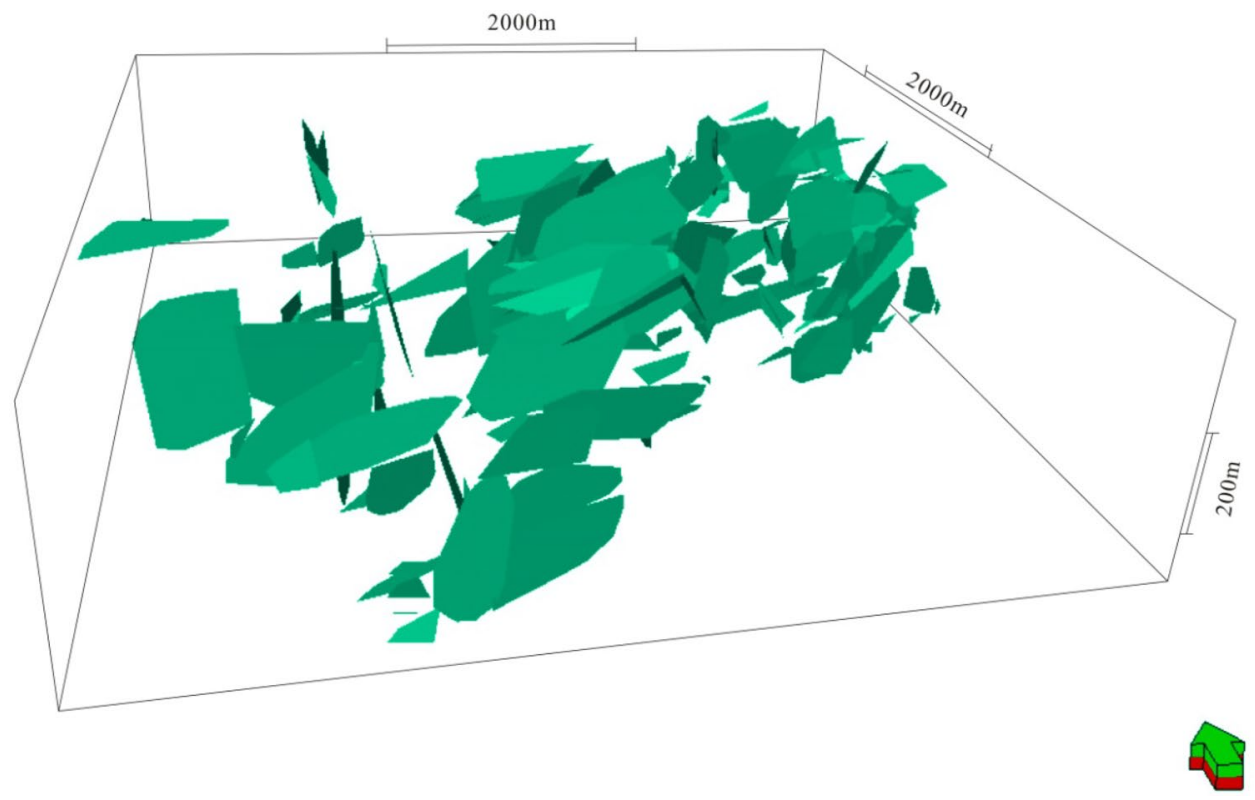

impedance effectively predicts the distribution of interwell sandbody. Ant body and water drive front data effectively predict fracture distribution. The established model can more effectively match the prior geological understanding of subsurface reservoirs and can be used to calculate the reserves and guide oil injection development. The reserves calculated by the model $\left(718.82 \times 10^{4} \mathrm{t}\right)$ were highly consistent with the actual reserves $\left(724.1 \times 10^{4} \mathrm{t}\right)$ with an error of approximately $7.4 \%$.

If water is injected along the direction of the fracture, the oil well on the water line increases rapidly and becomes severely flooded. For example, Well gs 8-5-1 located in the fracture is drilled into 3 water flooded layer and is put into operation for 2 months. The effects of wells parallel to the water line are beneficial with a the relative slow water cut and a longer stable production period. The oil wells are low-production if water is not injected along fractures.

The established model in this study can effectively guide the adjustment of injection-production well patterns and improve the development effect. The low permeability reservoir is widely distributed all over the world, and the modeling method proposed in this study can be applied to other oilfields with similar geological characteristics.

\section{Conclusion}

1. Sandbody of gravity flow channel and fractures are the two types of the low permeability reservoir space. Core and logging data effectively identify the sandbody in single wells, and seismic impedance predicts the distribution of inter-well sandbody. Ant body and water drive front data effectively predict fracture distribution.

2. This paper presents a three-dimensional geological modeling method for low permeability reservoirs based on core, logging, seismic and dynamic data. The threedimensional geological model of the matrix is established using the sequential indicator simulation method based on the characteristics of gravity flow reservoirs. The fracture model is built using ant-tracking technology and is modified by the rule of the development of the fractures reflected by the water flooding front and dynamic data. 
Table 1 Parameters of some fractures of Maxi Oilfield

\begin{tabular}{|c|c|c|c|}
\hline Number & Azimuth & Dip direction & Dip \\
\hline 1 & 24.07 & 114.07 & 72.48 \\
\hline 2 & 34.01 & 124.01 & 33.75 \\
\hline 3 & 64.22 & 154.22 & 77.23 \\
\hline 4 & 50.07 & 140.07 & 53.57 \\
\hline 5 & 57.27 & 147.27 & 53.34 \\
\hline 6 & 67.34 & 157.34 & 77.1 \\
\hline 7 & 71.46 & 161.46 & 44.25 \\
\hline 8 & 68.05 & 158.05 & 8.11 \\
\hline 9 & 63.84 & 153.84 & 60.39 \\
\hline 10 & 32.74 & 122.74 & 21.4 \\
\hline 11 & 31.26 & 121.26 & 54.7 \\
\hline 12 & 59.03 & 149.03 & 57.73 \\
\hline 13 & 63 & 153 & 90 \\
\hline 14 & 59.6 & 149.6 & 42.54 \\
\hline 15 & 31.72 & 121.72 & 6.12 \\
\hline 16 & 55.16 & 145.16 & 62.11 \\
\hline 17 & 50.18 & 140.18 & 15.71 \\
\hline 18 & 59.22 & 149.22 & 81.32 \\
\hline 19 & 61.6 & 151.6 & 42.03 \\
\hline 20 & 64.4 & 154.4 & 70.51 \\
\hline 21 & 53.27 & 143.27 & 84.73 \\
\hline 22 & 56.36 & 146.36 & 58.07 \\
\hline 23 & 63.99 & 153.99 & 87.99 \\
\hline 24 & 75.7 & 165.7 & 88.42 \\
\hline 25 & 30.12 & 120.12 & 63.9 \\
\hline 26 & 66.45 & 156.45 & 82.26 \\
\hline 27 & 49.67 & 139.67 & 78.34 \\
\hline 28 & 49.32 & 139.32 & 30.86 \\
\hline 29 & 54.85 & 144.85 & 86.39 \\
\hline 30 & 53.94 & 143.94 & 85.16 \\
\hline 31 & 49.08 & 139.08 & 26.56 \\
\hline 32 & 30.12 & 120.12 & 52.79 \\
\hline 33 & 53.3 & 143.3 & 28.12 \\
\hline 34 & 58.13 & 148.13 & 76.87 \\
\hline 35 & 68.25 & 158.25 & 15.33 \\
\hline 36 & 66.36 & 156.36 & 78.46 \\
\hline 37 & 63 & 153 & 90 \\
\hline 38 & 59.22 & 149.22 & 61.84 \\
\hline 39 & 54.67 & 144.67 & 85.46 \\
\hline
\end{tabular}



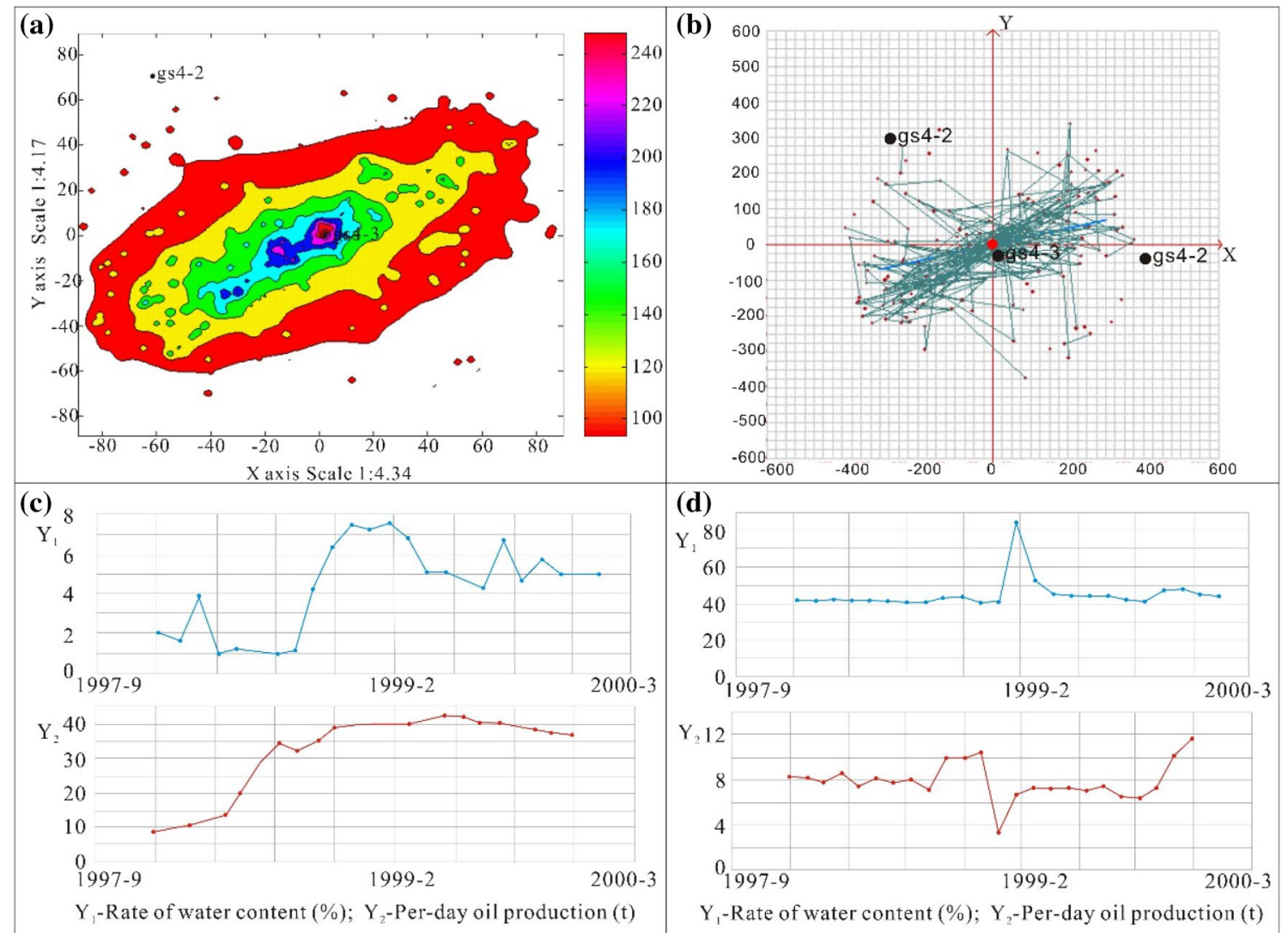

Fig. 9 Prediction of fractures using dynamic data in Maxi Oilfield. a Fitting map of waterflooding front of Well gs4-3. b Fractures near Well gs4-3. c Water and oil production curve Well gs4-4-1. d Water and oil production curve Well gs4-2

Acknowledgements This study was funded by the National Science and Technology Key Project (No. 2016ZX05014-002).

Open Access This article is distributed under the terms of the Creative Commons Attribution 4.0 International License (http://creativeco mmons.org/licenses/by/4.0/), which permits unrestricted use, distribution, and reproduction in any medium, provided you give appropriate credit to the original author(s) and the source, provide a link to the Creative Commons license, and indicate if changes were made.

\section{References}

Aarnes JE (2004) On the use of a mixed multi-scale finite element method for greater flexibility and increased speed or improved accuracy in reservoir simulation. Multiscale Model Simul $2: 421-439$

Chen GX, Zhao F, Cao ZL et al (2014) Integrated reservoir modeling based on seismic inversion and geological data. Natural Gas Geosci 25:1839-1846

Deutsch CV (2006) A sequential indicator simulation program for categorical variables with point and block data: BlockSIS. Comput Geosci 32:1669-1681

Journel AG (1983) Nonparametric estimation of spatial distribution. Math Geol 15:445-468

Journel AG, Alabert FG (1988) Focusing on spatial connectivity of extreme-valued attributes: stochastic indicator models of reservoir heterogeneities. In: Society of petroleum engineers 63rd annual technical conference, SPE Paper 18324

Lang XL, Guo SJ (2013) Fractured reservoir modeling method based on discrete fracture network model. Acta Sci Nat Univ Pekinensis 49:964-972

Luo RT, Wei HM, Chen J (2016) A fracture prediction method based on ant tracer technique: a case history of carbonate rock of Es 4 of the east of the south slope of Dongying sag. Pet Geophys 14:22-25

Pyrcz MJ, Deutsch CV (2014) Geostatistical reservoir modeling. Oxford University Press, Oxford

Tureyen OI, Caers J (2005) A parallel, multiscale approach to reservoir modeling. Comput Geosci 9:75-98

$\mathrm{Xu}$ WS, Gong B, He C et al (2011) Modeling of reservoir fractures based on discrete fracture network. J Daqing Pet Inst 35:13-16

Yao FC, Gan LD (2000) Application and restriction of seismic inversion. Pet Explor Dev 27:53-56 + 10

Yao J, Wang ZS, Zhang Y, Huang CQ (2010) Numerical simulation method of discrete fracture network for naturally fractured reservoirs. Acta Pet Sin 31:284-288

Zhou W, Yin TJ, Zhang YC et al (2015) Application of ant tracking technology to fracture prediction: a case study from Xiagou formation in Qingxi Oilfield. Lithol Reserv 27:111-118

Publisher's Note Springer Nature remains neutral with regard to jurisdictional claims in published maps and institutional affiliations. 